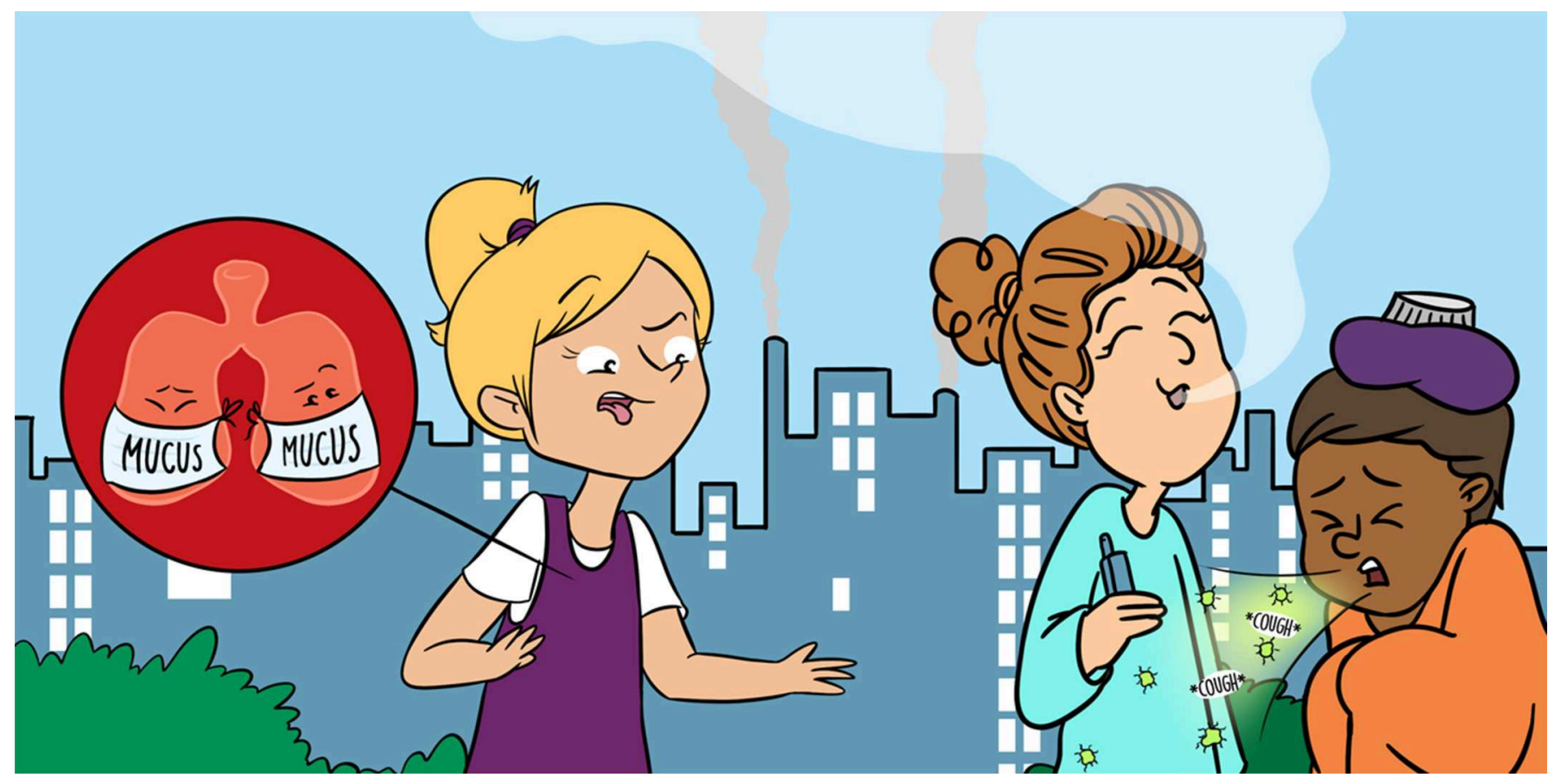

\title{
MOVING MUCUS MATTERS FOR LUNG HEALTH
}

\section{Mason Weupe ${ }^{1,2,3 t}$, Jacelyn E. Peabody Lever ${ }^{1,2,4,5 t}$, Jared P. Kennemur ${ }^{1,2,4}$, Taylor R. Bono ${ }^{1,2,4}$, Scott E. Phillips ${ }^{1,2,4}$, Ren-Jay Shei $i^{1,2,4}$ and Steven M. Rowe ${ }^{1,2,4,6,7^{*}}$}

${ }^{1}$ Steven M. Rowe Laboratory, University of Alabama at Birmingham, Birmingham, AL, United States

${ }^{2}$ Gregory Fleming James Cystic Fibrosis Research Center, University of Alabama at Birmingham, Birmingham, AL, United States ${ }^{3}$ Preparation for Graduate and Medical Education Program, University of Alabama at Birmingham, Birmingham, AL, United States ${ }^{4}$ Department of Medicine, University of Alabama at Birmingham, Birmingham, AL, United States

${ }^{5}$ Medical Scientist Training Program, University of Alabama at Birmingham, Birmingham, AL, United States

${ }^{6}$ Department of Pediatrics, University of Alabama at Birmingham, Birmingham, AL, United States

${ }^{7}$ Cell Developmental and Integrative Biology, University of Alabama at Birmingham, Birmingham, AL, United States

YOUNG REVIEWERS:

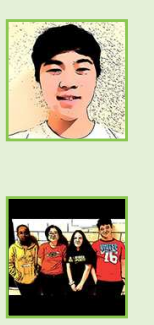

ALLEN

AGE: 14

TAPPAN

MIDDLE

SCHOOL

AGES: $12-13$
When we breathe, the lungs exchange oxygen from the air for carbon dioxide waste from the blood. This exchange is vital for life. Each breath exposes the lungs to the outside environment, which contains pollution and germs, posing a threat to our health. The first line of defense is called the mucociliary escalator: mucus traps the potentially dangerous material and cilia push that material up and out of our airways. When the mucociliary escalator is not working properly, we may develop lung disease. For example, patients with genetic diseases like cystic fibrosis (CF) and primary ciliary dyskinesia (PCD), or smoking-related diseases like chronic obstructive pulmonary disease (COPD) have extremely thick mucus. This mucus builds up, allowing bacteria, fungi, and viruses to thrive, causing lung damage and decreased oxygenation. Lung 
GAS EXCHANGE

The process by which carbon dioxide $\left(\mathrm{CO}_{2}\right)$ waste is removed from the blood stream and replaced by inhaled oxygen $\left(\mathrm{O}_{2}\right)$.

\section{ALVEOLI}

Air sacs that make up the smallest portion of the respiratory zone; alveoli and capillary blood vessels are in very close proximity; this is where gas exchange occurs.

\section{CONDUCTING}

ZONE

The portion of the respiratory tract that is not involved in gas exchange; the purpose of the conducing zone is to move air to and from the respiratory zone; where the mucociliary escalator is located; found in the proximal lung from the trachea to the bronchioles.

\section{RESPIRATORY ZONE}

The portion of the respiratory tract where gas exchange occurs; found in the distal lung where alveoli are located.

\section{CILIA}

Mobile, hair-like projections on the top part of cells lining the conducting zone airways; cilia move mucus along the mucociliary escalator.

\section{diseases make breathing extremely difficult, and patients can have life-threatening respiratory illness when the mucociliary escalator cannot maintain lung health.}

\section{HOW DO THE LUNGS WORK?}

The primary function of the lungs is breathing. Gas exchange is the name of the process by which oxygen enters the bloodstream (from inhalation) and carbon dioxide waste leaves the body (from exhalation). The structure of the lung has evolved to perform this task very efficiently. The basic structure of the lungs is a series of hollow tubes, called airways. Airways branch and get smaller, ending in tiny air sacs called alveoli. Alveoli are covered in small blood vessels named capillaries, which function to exchange gases in the blood [1]. The lungs can be compared to a tree that has a large, main trunk with branches becoming smaller the further away they are from the trunk. The alveoli are like the leaves.

There are two main regions in the lung: the conducting zone and the respiratory zone (Figure 1). Air is carried into the lungs through the conducting zone and brought to the alveoli-containing respiratory zone. The alveoli from one person have the same surface area as a tennis court, which is plenty of area to allow for gas exchange. The conducting zone is the part of the lung that air flows through without any gas exchange, because the tubes are too thick for the gases to move across. The conducting zone is lined with hair-like structures called cilia that are covered in mucus, which helps trap potentially dangerous materials. Cilia are mobile, tiny, finger-like projections on the surface of airway cells. Cilia line the airways and help move mucus up and out of the lungs [5]. Cilia are about 6-7 micrometers tall, or roughly a tenth the width of a human hair $[3,5]$.

\section{PARTICLES AND GERMS IN THE AIR-WHY THE LUNGS NEED DEFENSE}

There are many types of particles that could enter the lungs and cause damage. Some of these particles are pollutants, such as emissions from gas-powered vehicles, carbon monoxide from fireplaces, toxins from vaping or smoking, and aerosols like hairspray. Particles can get trapped in various areas of the lung. Short hairs, like the kind on top of your head, line the insides of the nostrils and are covered with mucus. These mucus-covered hairs help trap larger particles as they enter the nose. Particles that enter the conducting zone can hurt the airway cells, which may reduce the movement of their cilia and lead to a buildup of mucus that cannot be cleared from the airways [2]. Mucus-clogged airways may not allow air to travel as effectively, like the way leaves in a gutter interfere with water flow. 
Figure 1

The mucociliary escalator in a healthy person (left) and in a person with a diseased mucociliary escalator (right). The mucociliary escalator is found in the trachea, bronchi, and bronchioles, which are part of the conducting zone. Gas exchange occurs in the alveoli in the respiratory zone (inset).

\section{MUCUS}

Sticky, gel-like substance which sits on top of the cilia brush in the conducting zone airways; in the lungs, mucus is made by goblet cells and glands and functions to protect the airways from dangerous materials; mucus is composed of water, mucin glycoproteins, defense proteins, and salt.

\section{MUCOCILIARY ESCALATOR}

Term for the apparatus of mucus and cilia; responsible for movement of mucus up and out of the respiratory tract; mucus traps particles and cilia propel mucus up and out of the lungs.

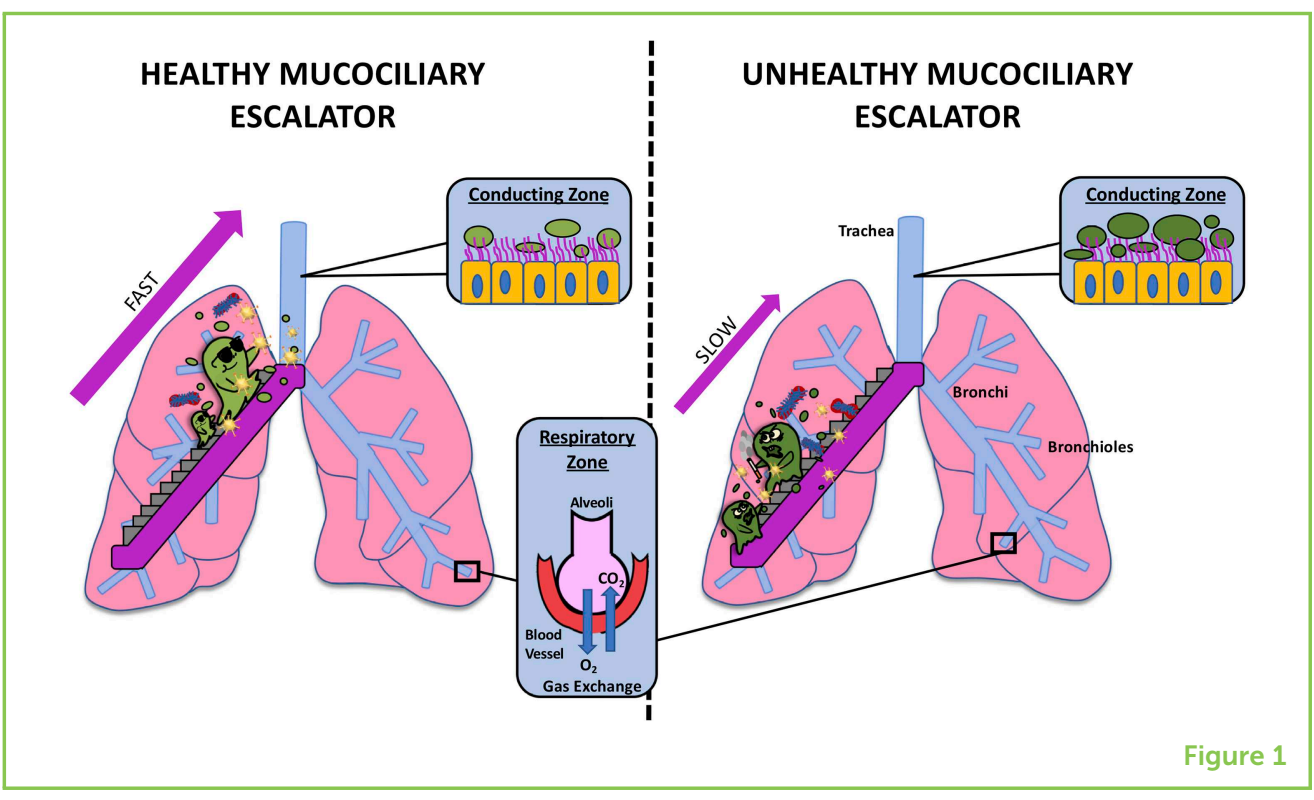

Smaller particles can sometimes get all the way to the alveoli. Damage to the alveoli makes breathing considerably more difficult, because oxygen will not diffuse as well into the blood. This reduced efficiency of gas exchange may cause the rest of the body to be hypoxic, which means low in oxygen. Only the conducting zone, from the trachea to the bronchioles, has the ability to move mucus using cilia, so alveoli cannot rely on this mechanism to get rid of these small particulates [3]. Living in a polluted city or years of smoking/vaping can cause the lung tissue to become inflamed and lead to diseases, such as chronic obstructive pulmonary disease (COPD) [4].

\section{WHAT IS THE MUCOCILIARY ESCALATOR?}

The mucociliary escalator is inside of the conducting airways and is made up of mucus and cilia, which moves the mucus up and out of the lungs where it can be expelled by coughing or swallowing (Figures 1, 2) [5]. As the first line of defense, airway mucus is made up of different components that help it trap particles and germs [2,4]. Mucus is a physical barrier to protect the lung and has properties that help get rid of potentially infectious bacteria, fungi, and viruses [4, 5]. Some of the important components of airway mucus are mucins (sticky, sugar-coated proteins), defense proteins, salt, and water. Together, these components form a gel that traps particles that enter the airway [2].

Mucus is mostly produced by cells that line the inside of the airways. These are called goblet cells. Goblet cells are shaped like medieval chalices, hence the name goblet. Unlike other cells in the airway that are ciliated and shaped like columns, goblet cells do not have cilia on top. Goblet cells are not present beyond the conducting zone, to prevent mucus from interfering with gas exchange. Mucus is also 
Figure 2

(Left) Cilia in healthy airways are mobile and able to move mucus efficiently up the mucociliary escalator (Middle) In CF, mucus becomes thick and difficult to move, causing the mucociliary escalator to be less efficient; this allows germs/particles to be trapped, eventually causing lung damage. (Right) In PCD, cilia are less mobile or even immobile, making them unable to move mucus up the mucociliary escalator.

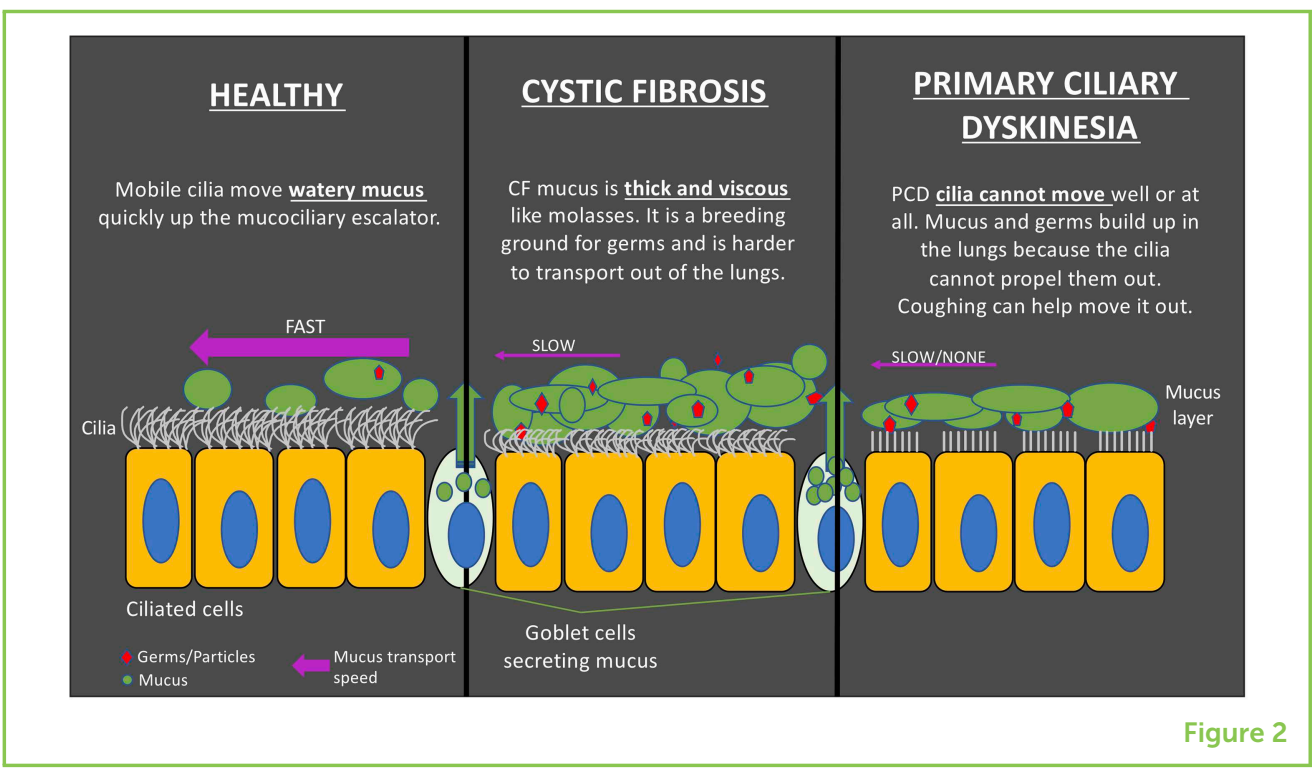

involved in the hydration of airways, which is necessary for proper function of the cilia [3,5].

The movement of cilia is similar to the way your arms move while swimming the breaststroke [3]. An individual cilium is not strong enough to move the mucus layer on its own, but when thousands of cilia beat together in a coordinated fashion, they can collectively cause the mucus to move $[2,3]$. Imagine a crowd at a concert when the performer dives off the stage to crowd surf: the performer is like a bundle of mucus, being held up by the arms of the crowd and moved along in a coordinated wave. In a sense, the cilia talk to each other through movement to produce coordinated, efficient movement of the mucus! This is how the mucociliary escalator works.

\section{WHAT DISEASES CAN HAPPEN WHEN THE MUCOCILIARY ESCALATOR IS NOT WORKING CORRECTLY?}

Some people inherit abnormal genes from their parents and are born with a disease called primary ciliary dyskinesia (PCD) (Figure 2). PCD is a lung disease that prevents the cilia from beating effectively and, in severe cases, prevents them from moving at all [3]. In PCD patients, the airways become infected due to ineffective mucus transport, which damages the airway cells. When airways become damaged over time, they become floppy, like a collapsed straw, preventing air from moving through them and causing breathing to become difficult. Imagine drinking a thick, delicious milkshake; less effort is required when you use a normal-width straw compared with a straw that is the width of a spaghetti noodle.

Cystic fibrosis (CF) is another inherited disease that affects the mucociliary escalator [3] (Figure 2). People with CF have mutations 
in both copies of the gene (one from mom and one from dad) responsible for making a protein called cystic fibrosis transmembrane conductance regulator (CFTR). CFTR forms a channel across the membranes of cells that is involved in the production of sweat, digestive fluids, and mucus. CFTR regulates how much water ends up in these secretions and thus how thick and sticky the mucus becomes. When the channel does not work correctly, the mucus does not have enough water and becomes thick, like glue. The extraordinarily thick mucus accumulates in the lungs, unlike normal, watery mucus that is easily cleared by the mucociliary escalator, causing the thick mucus to build up and eventually cause airway destruction and lung failure.

Chronic obstructive pulmonary disease (COPD) is a disease that can occur after smoking cigarettes or vaping e-cigarettes. COPD can negatively impact the mucociliary escalator and cause lung disease that looks similar in many ways to CF [3]. Damage to the mucociliary escalator can contribute to other common diseases like pneumonia and asthma, which have similar, but sometimes less severe, problems of mucus.

\section{CONCLUSION: WHY MUCUS, CILIA, AND THE MUCOCILIARY ESCALATOR MATTER}

Proper function of the mucociliary escalator is required for healthy lungs. Mucus and cilia are a primary defense mechanism for the lungs. If there is a problem with either the mucus or the cilia, the airways may become blocked and the harmful germs and particles can be trapped in the lungs, causing damage. Genetic diseases like PCD and CF and acquired diseases like COPD negatively impact the mucociliary escalator. These lung diseases can result in less gas exchange and cause the rest of the body to become hypoxic. So remember-when you are home sick with a cold, the mucus you are coughing up is from your mucociliary escalator, and it is helping to keep your lungs happy and healthy by removing potentially damaging particles and germs!

\section{AUTHOR CONTRIBUTIONS}

MW, JP, JK, TB, SP, R-JS, and SR contributed to the manuscript preparation and final editing. All authors approved the final manuscript draft before submission.

\section{ACKNOWLEDGMENTS}

The authors would like to acknowledge George D. Phillips (age 13), S. Corinne Phillips (age 16), and Andrew Rowe (age 14) for reading 
the manuscript and their thoughtful edits and feedback. Jeremie Lever and Basil Bono for providing invaluable support for the completion of this project.

\section{REFERENCES}

1. West, J. B. 2012. West's Respiratory Physiology: The Essentials. 9th Edn. Baltimore, MD: Lippincott Williams \& Wilkins.

2. Knowles, M. R., and Boucher, R. C. 2002. Mucus clearance as a primary innate defense mechanism for mammalian airways. J. Clin. Invest. 109:571-7. doi: $10.1172 /$ jci15217

3. Peabody, J. E., Shei, R. J., Bermingham, B. M., Phillips, S. E., Turner, B., Rowe, S. M., et al. 2018. Seeing cilia: imaging modalities for ciliary motion and clinical connections. Am. J. Physiol. Lung Cell. Mol. Physiol. 314:L909-21. doi: 10.1152/ajplung.00556.2017

4. Zhang, P., Summer, W. R., Bagby, G. J., and Nelson, S. 2000. Innate immunity and pulmonary host defense. Immunol. Rev. 173:39-51. doi: 10.1034/j.1600-065X.2000.917306.x

5. Bustamante-Marin, X. M., and Ostrowski, L. E. 2017. Cilia and mucociliary clearance. Cold Spring Harbor Perspect. Biol. 9:a028241. doi: 10.1101/cshperspect.a028241

SUBMITTED: 07 March 2019; ACCEPTED: 02 August 2019; PUBLISHED ONLINE: 11 September 2019.

EDITED BY: Valeria Costantino, University of Naples Federico II, Italy

CITATION: Weupe M, Peabody Lever JE, Kennemur JP, Bono TR, Phillips SE, Shei R-J and Rowe SM (2019) Moving Mucus Matters for Lung Health. Front. Young Minds 7:106. doi: 10.3389/frym.2019.00106

CONFLICT OF INTEREST STATEMENT: SR has an unlicensed patent use of micro-Optical Coherence Tomography as a diagnostic device, which is used to characterize the functional microanatomy of the mucociliary escalator.

The remaining authors declare that the research was conducted in the absence of any commercial or financial relationships that could be construed as a potential conflict of interest.

COPYRIGHT @ 2019 Weupe, Peabody Lever, Kennemur, Bono, Phillips, Shei and Rowe. This is an open-access article distributed under the terms of the Creative Commons Attribution License (CC BY). The use, distribution or reproduction in other forums is permitted, provided the original author(s) and the copyright owner(s) are credited and that the original publication in this journal is cited, in accordance with accepted academic practice. No use, distribution or reproduction is permitted which does not comply with these terms. 

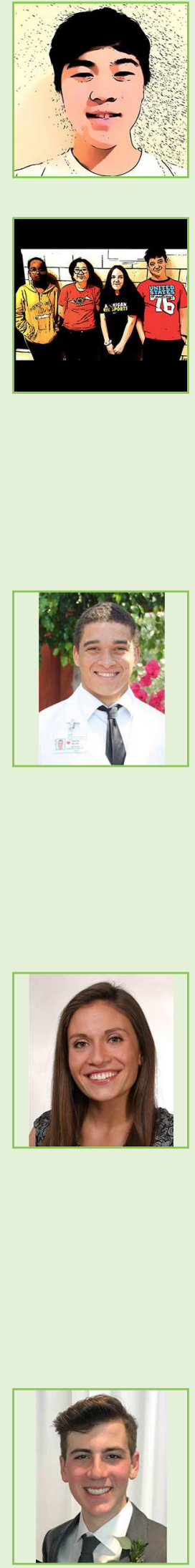

\section{YOUNG REVIEWERS}

\section{ALLEN, AGE: 14}

My name is Allen. I love to play soccer, swim competitively, and listen to music. I have also played the clarinet for almost 4 years, and piano for almost 2 years. In school, my favorite subjects are math and biology. When I grow up, I want to work in the field of molecular biology.

\section{TAPPAN MIDDLE SCHOOL, AGES: 12-13}

This article was reviewed by Maria, Evyatar, Noa, and Charlotte. We are a group of cheery and bright seventh graders in Ms. Frantom's science class at Tappan Middle School in Ann Arbor, Michigan, USA. Tappan students in sixth through eighth grade achieve at high levels under the facilitation of skilled, effective, culturally competent educators. We completed this review with the help of our science mentors, Dr. Pamela Wong and Matthew Ruge.

\section{AUTHORS}

\section{MASON WEUPE}

Mason Weupe is an undergraduate senior at the University of California, Irvine majoring in Public Health Sciences. He aspires to earn an M.D./Ph.D. degree. He recently conducted research at the University of Alabama at Birmingham in lung disease, as a part of the Preparation for Graduate and Medical Education (Paradigm) Summer Medical Scientist Training Research Internship. As a result of his newfound knowledge, he worked with his mentors in the Rowe lab to write an article summarizing a portion of the research project because he wanted to facilitate science communication and share the mucociliary escalator with the Frontiers for Young Minds readers. orcid.org/0000-0002-1181-2069

\section{JACELYN E. PEABODY LEVER}

Jacelyn E. Peabody Lever is in her fifth year in the Medical Scientist Training Program (M.D./Ph.D.) at UAB. Additionally, Jacelyn is pursuing the Mentoring and Leadership Graduate Certificate. A personal history of asthmatic disease, diverse research experiences, and love of solving complex problems has motivated Jacelyn to become a physician-scientist pulmonologist. Her thesis project is discovering the mechanisms of pathologic mucus and a dysfunctional mucociliary escalator in the pulmonary fibrosis ferret (Rowe lab). Jacelyn graduated magna cum laude from Carthage College (Biology and Neuroscience double-major; Classical Studies minor). She was the Outstanding UAB Woman Graduate Student of 2018. Tweet ajacepeabody \#mucusmatters. orcid.org/0000-0003-3490-8474

\section{JARED P. KENNEMUR}

Jared P. Kennemur is a sophomore undergraduate student at University of Alabama at Birmingham, pursuing a major in Biology with a minor in Chemistry. His goal is to practice medicine as a licensed physician. Jared recently began doing research in the Rowe laboratory focusing on idiopathic pulmonary fibrosis, which is where he discovered his love for all things lungs. In the future, he would like to continue doing biomedical research and maybe 1 day run a lab of his own. He is an active member 

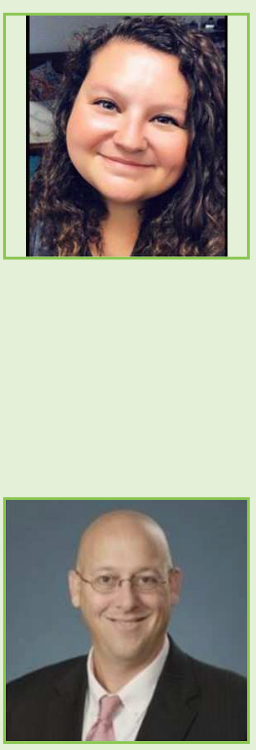

of the Association of Advocates for Women in Science and Medicine (AAWSM). orcid.org/0000-0003-2777-2054

\section{TAYLOR R. BONO}

Taylor R. Bono is a third year medical student at UAB and Outstanding UAB Woman Graduate Student for 2019. Her career goal is to be a physician-scientist pulmonologist and to have a clinical practice based in personalized, bench-to-bedside medicine. She is also a researcher at UAB's Cystic Fibrosis Research Center, where she studies cystic fibrosis. Taylor volunteers at UAB's student-run free clinic for underserved populations, STEM outreach programs in elementary schools, and advocates for STEM women. Taylor graduated with a degree in Biology and minor in Chemistry. Tweet ataylor_bono. orcid.org/0000-0003-0588-539X

\section{SCOTT E. PHILLIPS}

Dr. Scott E. Phillips is a Scientist in the lab of Dr. Rowe at UAB. Dr. Phillips received his B.S. degrees in Microbiology and Environmental Science from Auburn University and Ph.D. from the University of North Carolina at Chapel Hill in Cell and Developmental Biology. After completing his post-doctoral training at Vanderbilt University studying Niemann-Pick disease, Dr. Phillips came to UAB and worked in the Department of Neurobiology with Drs. Wilson and Sweatt. His current work with Dr. Rowe focuses on developing a unique ferret model of IPF to better understand the contribution of mucociliary dysfunction to the disease state. orcid.org/0000-0002-5451-0984

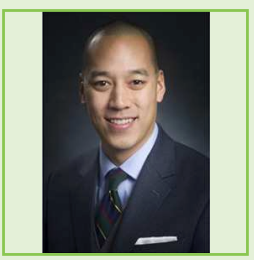

\section{REN-JAY SHEI}

Dr. Ren-Jay Shei is a translational scientist completing his post-doctoral training under the mentorship of Dr. Rowe at UAB. He is an exercise physiologist by training, with a focus on respiratory limitations to exercise in health and pulmonary diseases, including asthma and exercise-induced asthma. Dr. Shei received dual B.S. degrees in Exercise Science and Biology, an M.S. in Exercise Physiology, and Ph.D. in Human Performance, all from Indiana University. His current work embraces lung physiology research from basic discovery to translational science and clinical application. Dr. Shei is an Editorial Board member of Frontiers in Physiology (Integrative Physiology specialty section). orcid.org/0000-0002-7733-643X



\section{STEVEN M. ROWE}

Dr. Steven M. Rowe is a pioneer in the field of personalized therapeutics for cystic fibrosis (CF), cutting-edge discovery in airway disease biology, and translational research in COPD. He is an international authority in the design and conduct of clinical trials targeting the basic CF-defect, and has made key advances in the measurement and interpretation of CFTR function. Dr. Rowe co-invented an imaging technique called one-micron resolution Micro-OCT that captures real-time videos of functional micro-anatomy of the mucociliary escalator. He is Director of the Gregory Fleming Cystic Fibrosis Research Center, which involves over 100 faculty members and has been continuously funded for over 25 years. *srowe@uabmc.edu orcid.org/0000-0001-9045-0133

${ }^{\dagger}$ These authors have contributed equally to this work 